\title{
Moorfields cataract surgery recovery pilot during the Covid-19 pandemic
}

\author{
James J. L. Tee ${ }^{1}$ Huda Al-Hayouti ${ }^{1} \cdot$ Mary Masih $^{1} \cdot$ Badrul Hussain $^{1} \cdot$ Alex lonides $^{1} \cdot$ Vincenzo Maurino $^{1}$
}

Received: 5 October 2020 / Revised: 7 November 2020 / Accepted: 9 November 2020 / Published online: 21 January 2021

(c) The Royal College of Ophthalmologists 2020

\section{To the Editor:}

Cataract surgery was stopped in March 2020 consequent to the Covid-19 pandemic. A planned return was piloted at Moorfields Eye Hospital at St Ann's, London in June 2020. In response to the article by Darcy et al. [1], and in conjunction with national guidelines on cautious reopening of surgical services [2,3], we describe our pilot together with an analysis of the first 50 patients operated on.

A stratification exercise based on visual acuity, visual disablement and systemic vulnerability to Covid-19 was conducted on all cases listed for surgery prior to national lockdown. Telephone consultations were performed to evaluate change in vision, systemic health and patient willingness to undergo surgery. Information and instruction leaflets, updated consent forms incorporating Covid-19 risk, Covid-19 self-swab kits and pupil dilating eyedrops were posted out to patients before surgery. Swabs were later collected by courier for laboratory testing.

Arrival times on day of surgery were staggered at halfhour intervals to a maximum of five patients per four-hour list. Staff members and patients were screened at the entrance and a one-way system instituted throughout the unit. Surgical staff wore appropriate personal protective

These authors contributed equally: James J. L. Tee, Huda Al-Hayouti These authors jointly supervised this work: Alex Ionides, Vincenzo Maurino

James J. L. Tee

j.tee@ucl.ac.uk

1 Moorfields Eye Hospital NHS Foundation Trust, 162 City Road, London EC1V 2PD, UK equipment. Techniques shown to reduce aerosolisation were utilised where possible during phacoemulsification: use of 2.2-mm phaco tip [1], hydroxypropyl methylcellulose application on corneal incision [1], tip placement away from corneal incision [4], in addition to routine use of povidoneiodine for cleaning and complete viscoelastic exchange of anterior chamber fluid before capsulorrhexis. Theatre floors were disinfected between cases and all surgery performed under local anaesthesia.

Only one complication (anterior capsular tear) was reported on a total of 118 patients operated on during the pilot. Table 1 shows an analysis of the first 50 patients. A large number of swab results were unavailable at the beginning despite 72-h turnaround time, mostly due to logistical delays. We operated on these patients as they fulfilled the 14-day self-isolation and were systemically well. Delays were resolved with timely feedback to laboratory teams.

Latest elective surgery guideline now recommends a reduced 3-day period of self-isolation, from day of Covid19 test to admission [5]. It is envisaged that more patients will be accepting of the shorter self-isolation requirements.

The self-dilating initiative has reduced admission time as patients arrive with dilated pupils ready for surgery. Postoperative drops were prescribed in advance to minimise discharge time following surgery.

We utilised telephone consults to minimise in-person hospital follow-up attendances. Only one patient from the 36 telephone consults required an urgent in-person review for anterior uveitis. The rest were satisfied with their visual improvement with no other concerns, and were listed for second eye surgery or discharged to their optometrist.

Training opportunities were reduced as an unintended consequence during the pilot. We have now reinstated cataract surgery training and have accommodated an increase to eight cases per list.

Our pilot has demonstrated the feasibility of conducting cataract surgery safely during the pandemic. We hope our 
Table 1 An analysis of the first 50 patients who underwent surgery during the Moorfields Covid-19 cataract surgery recovery pilot.

\begin{tabular}{llc}
\hline Parameter & Description & Number $(\%)$ \\
\hline Sex & Male & $27(54)$ \\
& Female & $23(46)$ \\
Age (range) & $63(41-75)$ years & \\
Covid-19 test result & Negative & $50(42)$ \\
& Pending at time of & $60(51)$ \\
& surgery & \\
Eye & Invalid test & $8(7)$ \\
& First & $23(46)$ \\
Snellen visual acuity & Second & $25(50)$ \\
Advanced cataract & Bilateral & $2(4)$ \\
& $\leq 6 / 12$ & $43(83)$ \\
Range of intraocular lens & $>6 / 12$ & $9(17)$ \\
implant power & Intumescent or & $6(12)$ \\
Surgeon grade & brunescent & \\
Follow-up & +29.00 to $-1.00 \mathrm{D}$ & \\
Anaesthesia type & Consultant & $28(54)$ \\
Complications & Fellow & $24(46)$ \\
Post-operative & Subtenons & $39(75)$ \\
Fopical & Anterior capsular tear & $13(25)$ \\
& Tn-person consult & $14(28)$ \\
& & $36(72)$ \\
\hline
\end{tabular}

In-person post-operative consults were required for the following reasons: intra-operative complication, potential for refractive surprise (eyes with previous refractive surgery, high myopia, toric intraocular lens implant), pre-existing macular pathology or dense cataract hindering pre-operative fundoscopy.

${ }^{a}$ Covid-19 test results are described for all 118 patients who underwent surgery during the pilot. experience will be beneficial to other centres here in the UK and abroad.

\section{Compliance with ethical standards}

Conflict of interest The authors declare that they have no conflict of interest.

Publisher's note Springer Nature remains neutral with regard to jurisdictional claims in published maps and institutional affiliations.

\section{References}

1. Darcy K, Elhaddad O, Achiron A, Keller J, Leadbetter D, Tole D, et al. Reducing visible aerosol generation during phacoemulsification in the era of Covid-19. Eye. 2020. https://doi.org/10.1038/ s41433-020-1053-3.

2. Royal College of Ophthalmologists. Guidance on the resumption of cataract services during COVID 2020. https://www.rcophth.ac. uk/wp-content/uploads/2020/05/Resumption-of-Cataract-ServicesDuring-COVID-1.pdf. Accessed 17 Jul 2020.

3. Royal College of Ophthalmologists. Cataract surgery guidelines for Post COVID-19 pandemic: recommendations https://www.rcophth. ac.uk/wp-content/uploads/2020/05/RCOphth-UKISCRS-COVIDcataract-surgery-restoring-services-070520.pdf. Accessed $23 \mathrm{Jul}$ 2020.

4. Shetty N, Kaweri L, Khamar P, Balakrishnan N, Rasheed A, Kabi $\mathrm{P}$, et al. Propensity and quantification of aerosol and droplet creation during phacoemulsification with high-speed shadowgraphy amid COVID-19 pandemic. J Cataract Refract Surg. 2020;46:1297-301.

5. National Institute for Health and Care Excellence. Covid-19 rapid guideline: arranging planned care in hospitals and diagnostic services. 2020. https://www.nice.org.uk/guidance/ng179. Accessed 6 Sep 2020. 